\title{
Traumatic Brachial Arteriovenous Fistula - History Also Matters
}

\author{
Debasish Das ${ }^{1}$, Debasis Acharya ${ }^{2}$, Jogendra Singh ${ }^{3}$, Subhas Pramanik ${ }^{4}$ \\ 1, 2, 3, 4 Department of Cardiology, All India Institute of Medical Sciences (AIIMS), Bhubaneswar, Odisha, India.
}

\section{INTRODUCTION}

Transradial intervention usually does not mandate history of arm or forearm injury; we report a case of traumatic AV fistula with focal narrowing of brachial artery for which right transradial angiogram could not be performed and coronary angiogram was accomplished from left transradial access. This rare case teaches us the fact that planning a transradial intervention also requires a history of trauma or surgical intervention to arm or forearm to avoid inadvertent complications during transradial access.

Communication between an artery and a vein is known as arteriovenous fistula (AVF) which may be congenital, acquired or surgically created. Acquired arteriovenous fistula is most commonly due to traumatic injury. Following vascular injury, a hematoma develops locally, local healing and fibrosis leads to adhesion between artery and vein creating an arteriovenous fistula. ${ }^{1}$

Large arteriovenous fistula results in high output cardiac failure and rarely accounts for chronic ischaemia. ${ }^{2}$ Degree of arteriovenous shunting decides the timeframe of clinical presentation which is often subtle with delay in diagnosis. We report a case of post traumatic brachial AV fistula presenting with feeble pulse, difficult radial puncture and right transradial access failure with switch over to right transfemoral access for accomplishing coronary intervention.

\section{PRESENTATION OF CASE}

A 65-year-old gentleman presented with acute anterior wall ST elevated myocardial infarction and was subjected to elective right transradial coronary angiogram. Right transradial puncture was not possible due to feeble radial pulse and left transradial angiogram was accomplished which revealed double vessel disease and was planned for percutaneous coronary intervention to left anterior descending artery (LAD) and left circumflex artery (LCX). In the next setting, right transradial access was obtained with difficulty but terumo guide wire was not able to cross the mid segment of brachial artery and brachial angiogram revealed focal narrowing and tortuosity of brachial artery with brachial arteriovenous fistula with local run off resulting in feeble radial pulse.
Corresponding Author: Dr. Debasish Das, Assistant professor, Department of Cardiology, All India Institute of Medical Sciences (AIIMS), Bhubaneswar, Odisha, India.

E-mail:dasdebasish54@gmail.com

DOI: $10.14260 / j e m d s / 2021 / 417$

How to Cite This Article:

Das D, Acharya D, Singh J, et al. Traumatic brachial arteriovenous fistula - history also matters. J Evolution Med Dent Sci 2021;10(27):2042-2043, DOI: $10.14260 /$ jemds/2021/417

Submission 24-02-2021,

Peer Review 05-05-2021,

Acceptance 12-05-2021,

Published 05-07-2021.

Copyright (C) 2021 Debasish Das et al. This is an open access article distributed under Creative Commons Attribution License [Attribution 4.0 International (CC BY 4.0)] 
History revealed that he had met with an accident of right forearm five years back and had undergone surgical fixation of fractured right shaft of humerus. Angioplasty was accomplished through right transfemoral route. Obtaining a proper history also accounts a lot in planning and executing a safe transradial intervention. Inadvertent passage of slender and slippery terumo wire in such cases can result in brachial perforation and landing in catastrophe.

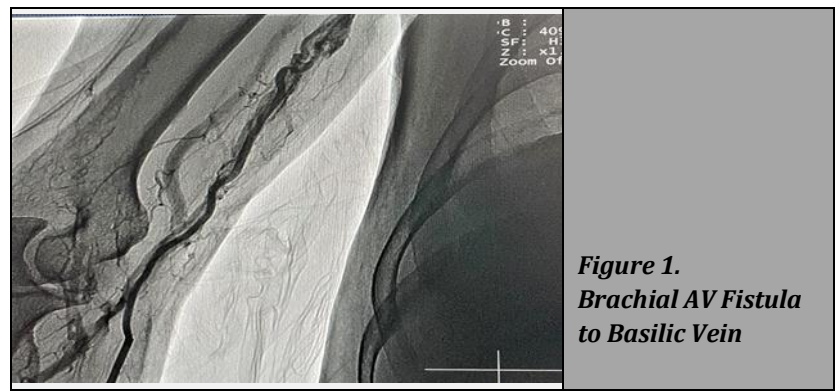

\section{DISCUSSION}

Nurick described the first case of traumatic arteriovenous fistula of the upper limb in the proceedings of Royal Society of Medicine in 1953; the person had suffered from a gunshot injury in axilla 36 years back. ${ }^{3}$ Paucity of case reports exists on traumatic brachial arteriovenous fistula till now. 4,5 Traumatic arteriovenous fistulae with steal syndrome are a rarity as presented in our case with feeble distal radial pulse with difficult right transradial access. Arteriovenous fistula is repaired by primary repair or vein or PTFE patch repair after disconnecting the fistula between artery and vein. ${ }^{6}$ Loughlin et al. described brachial AV fistula to vena comitans; surgical management of which includes aneurysmectomy, interposition cephalic vein grafting and lateral repair of vena comitans. ${ }^{7}$ Our case was not extreme form of brachial steal syndrome; so post coronary angioplasty we advised the patient to take beta blockers to prevent high output cardiac failure and regular follow up.

\section{CONCLUSIONS}

We want to deliver the message to the budding interventionists that even history of trauma or surgical intervention plays a significant role in planning a safe transradial intervention. Our case is a beautiful illustration of traumatic brachial AV fistula which we would not have missed if we would have obtained a proper history during first transradial access. In intervention "history also matters."

Financial or other competing interests: None.

Disclosure forms provided by the authors are available with the full text of this article at jemds.com.

\section{REFERENCES}

[1] Kotagal M, Reiss A, Vo N, et al. Iatrogenic arteriovenous fistula in the arm in an infant: diagnostic and therapeutic considerations J Clin Ultrasound 2012;40(6):381-4.

[2] Papes D, Snajdar I, Cavar S, et al. Pediatric iatrogenic arteriovenous fistulas. Am Surg 2019;85(5):e262-5.

[3] Nurick AW. Traumatic arteriovenous fistula. Proc R Soc Med 1953;46(5):310.

[4] Acsady G, Mogan I, Szabo I, et al. Traumatic arteriovenous fistulas of the arm. Magy Traumatol Orthop Helyreallito Seb 1987;30(1):39-46.

[5] Chuanwu J, Bin Z, Hai Z. Images in vascular medicine. Traumatic arteriovenous fistula in the forearm. Vasc Med 2013;18(2):112-3.

[6] White RA, Scher LA, Samson RH, et al. Peripheral vascular injuries associated with falls from heights. J Trauma 1987;27(4):411-4.

[7] Loughlin V, Beniwal JS. Post-traumatic brachial artery aneurysm and arteriovenous fistulae. J Cardiovasc Surg (Torino) 1988;29(5):570-1. 